\title{
Improvements in Renal Replacement Therapy Practice Patterns in Estonia
}

\author{
Külli Kõlvalda Ülle Pechter ${ }^{a} \quad$ Merike Luman $^{b}$ Madis Ilmojac \\ Mai Ots-Rosenberg ${ }^{\text {a }}$ \\ ${ }^{a}$ Department of Internal Medicine, Tartu University, Tartu, ${ }^{b}$ Department of Nephrology, \\ North Estonian Regional Hospital, and ' Department of Nephrology, West Tallinn Central \\ Hospital, Tallinn, Estonia
}

\section{Key Words}

Renal replacement therapy · Clinical performance indicators · Anaemia · Phosphate .

Calcium $\cdot$ Parathyroid hormone $\cdot$ Albumin $\cdot$ Dialysis adequacy $\cdot \mathrm{Kt} / \mathrm{V}$

\section{Abstract}

Background: The clinical performance indicators (CPI) are important tools to assess and improve the quality of renal replacement therapy (RRT). The aim of the current study was to compare the results of a longitudinal set of CPI in RRT patients and to determine the extent to which the guidelines for anaemia, calcium phosphate management and other CPI are met in Estonian renal centres. Methods: A long-term retrospective, observational, cross-sectional CPI analysis was undertaken in RRT patients from 2007 to 2011. The following CPI set of welldesigned measures based on good evidence was analysed: anaemia management variables, laboratory analyses of mineral metabolism, nutritional status variables and dialysis adequacy variables. Results: Relatively small changes in the analysed mean CPI values were noticed during the study period. In the course of the study, we noticed an improvement in anaemia control, but not all centres achieved the standard of $>80 \%$ of the dialysis patients with a haemoglobin $(\mathrm{Hb})$ level $>100 \mathrm{~g} / \mathrm{l}$. There was a trend of decreasing $\mathrm{Hb}$ concentrations below $125 \mathrm{~g} / \mathrm{l}$ in both haemodialysis (HD) and peritoneal dialysis (PD) patients. In 2011, hyperphosphataemia was present in $58 \%$ of the HD and $47 \%$ of the PD patients, whereas centre differences varied between 50 and $60 \%$ of both the HD and PD patients. HD adequacy was achieved in $77 \%$ of the HD patients. Conclusion: An improvement in the data collection was noticed, and the analysis of CPI allows renal centres to assess and compare their practices with others. The collection and evaluation of CPI of RRT patients is an important improvement and significantly increases the awareness of nephrologists. 


\section{Introduction}

Chronic kidney disease (CKD) is a growing public health problem in the world, and renal replacement therapy (RRT) national renal registries, including that of Estonia, have reported a continuous increase of RRT patients during the last decades [1]. Main factors responsible for the adequate management of RRT patients are RRT type, presence of anaemia, bone disease, nutritional status and dialysis adequacy. The publication of international guidelines has provided a basis for the development of measures and initiatives to improve RRT treatment quality $[2,3]$.

The last 2 decades have witnessed a better understanding of uremic toxicity, salt and water control, correction of anaemia and metabolic abnormalities in CKD dialysis patients [4]. Anaemia affects $60-80 \%$ of the patients with CKD, reduces their quality of life and is a risk factor for early death due to cardiac disease or stroke [5]. On the other hand, poor control of the calcium/phosphorus balance also appears to have long-term deleterious effects on patient survival in end-stage kidney disease patients, and this risk of death may increase further by poor serum albumin (S-Alb) levels reflecting inadequate nutrition [6]. Clinical performance indicators (CPI) in nephrology practice are viewed as standards for judging the quality of clinical care and are increasingly used to provide cost-effective healthcare. Audits based on these indicators are increasingly performed on national, regional and local levels [4]. The collection of CPI by Estonian nephrologists have been started recently in conjunction with the NephroQUEST collaborative project.

The aim of the current study was to compare the results of a longitudinal set of CPI in RRT patients and to determine the extent to which the guidelines for anaemia, calcium phosphate management and other CPI are met in RRT patient cohorts and separately in Estonian renal centres.

\section{Methods}

\section{Data Collection}

A retrospective, observational, cross-sectional study surveying CPI was undertaken to compare laboratory and clinical data in different RRT cohorts during a 5-year period. Prevalent RRT patient data in Estonia between 2007 and 2011 was evaluated. The study was performed with the collaboration of the authors' nephrology centres and 12 smaller haemodialysis (HD) units (with 2-20 patients in every unit) in Estonia. Clinical information was collected from hospital medical records and from registry database paper forms obtained from nephrology centres. All laboratory analyses were performed in certified laboratories.

\section{Clinical Performance Indicators}

Anaemia Management

Collected anaemia management variables were serum haemoglobin $(\mathrm{Hb})$ and the use of erythropoiesis stimulating agents (ESA). Severe anaemia was defined as having $\mathrm{Hb}$ levels $<100 \mathrm{~g} / \mathrm{l}$. The $\mathrm{Hb}$ target values in the current study ranged from 110 to $120 \mathrm{~g} / \mathrm{l}$, as defined in the European Best Practice Guidelines [2], which set a minimum target of $11 \mathrm{~g} / \mathrm{dl}$ but suggest not to go higher than $12 \mathrm{~g} / \mathrm{dl}$ in patients with severe cardiovascular disease. The local guidelines prescribe that $>80 \%$ of the dialysis patients should have $\mathrm{Hb}$ levels $>100 \mathrm{~g} / \mathrm{l}$. A high $\mathrm{Hb}$ level (>125 g/l) was found in 15\% of the HD patients.

Mineral Metabolism

Mineral metabolism management indicators were the following: serum phosphate (P; normal range $0.87-1.45 \mathrm{mmol} / \mathrm{l}$ ), ionized calcium (iCa; normal range $1.16-1.32 \mathrm{mmol} / \mathrm{l}$ ), 
total $\mathrm{Ca}$, corrected for albumin (tCa; normal range $2.15-2.55 \mathrm{mmol} / \mathrm{l}$ ) and parathyroid hormone (PTH; normal range 1.60-6.90 pmol/l). In patients with stage 5D CKD, the guidelines [3] suggest decreasing elevated phosphorus levels towards the reference range and serum calcium levels in the reference range. Thus, although hyperphosphataemia should be defined as $\mathrm{p}>1.45 \mathrm{mmol} / \mathrm{l}$, we locally accepted a phosphate level of $<1.6 \mathrm{mmol} / \mathrm{l}$. Hypercalcaemia was defined as an iCa level of $>1.32 \mathrm{mmol} / \mathrm{l}$ and hyperparathyroidism as a PTH value of $>21 \mathrm{pmol} / \mathrm{l}$.

Nutritional Status

The CPI collected for the characterization of nutritional status were the following: S-Alb, cholesterol and body mass index (BMI). Hypoalbuminaemia was defined as an S-Alb level of $<35 \mathrm{~g} / \mathrm{l}$. Hypercholesterolaemia was defined as serum cholesterol level of $>6.2 \mathrm{mmol} / \mathrm{l}$. A BMI of 18.5-25 indicated an optimal weight, while a BMI $<18.5$ suggested underweight, a BMI $>25$ indicated overweight and a BMI $>30$ suggested obesity [7]. The inflammatory status was evaluated using the C-reactive protein (CRP) level (normal range $<5 \mathrm{mg} / \mathrm{l}$ ).

Kidney Function in Kidney Transplantation Patients

Serum creatinine was collected in all kidney transplantation patients in 2010, and glomerular filtration rate (GFR) was estimated by using the CKD-EPI creatinine equation [8].

Delivered Dialysis Dose and Adequacy

The number of HD sessions/week and the last measured HD quality index were calculated [single-pool Kt/V and urea reduction ratio (URR)], and the HD access type of HD patients was collected. As the standard for dialysis adequacy, a minimum equilibrated $\mathrm{Kt} / \mathrm{V}$ of 1.2 calculated from pre- and postdialysis urea values and a URR of $65 \%$ were recommended by local guidelines during the current study [9].

Data Analysis

The data were analysed to calculate summary statistics including the maximum, minimum and average values (mean \pm standard deviation, SD). The prevalence was defined as the number of patients/million population alive and on RRT on December 31, 2011.

Ethics

The study has been approved by the Research Ethics Committee of the Tartu University (protocol No. 164/t-10), and the analyses were carried out at the Department of Internal Medicine of the Tartu University.

\section{Results}

\section{Data Collection and Background Epidemiological Data}

By December 31, 2011, there were 714 end-stage kidney disease patients, of whom 309 were on dialysis and 415 were kidney transplantation patients. The prevalence of RRT increased from 449 per million population in 2007 to 536 per million population in 2011. Kidney transplantation was the main RRT modality (53.2\% in 2007 and 56.7\% in 2011 from RRT patients). Peritoneal dialysis (PD) patients accounted for $30 \%$ of the dialysis patients in 2007 and only $22 \%$ in 2011 [10].

Clinical Performance Indicators

A summary of the studied CPI is provided in table 1. 
Table 1. Summary of the CPI studied between 2007 and 2011

\begin{tabular}{|c|c|c|c|c|}
\hline CPI & Year & HD & $\mathrm{PD}$ & $\mathrm{Tx}$ \\
\hline \multirow[t]{5}{*}{$\mathrm{Hb}, \mathrm{g} / \mathrm{l}$} & 2007 & $114.8 \pm 13.6$ & $114.4 \pm 13.0$ & $126.2 \pm 16.6$ \\
\hline & 2008 & $113.5 \pm 11.5$ & $119.0 \pm 12.2$ & $127.0 \pm 16.8$ \\
\hline & 2009 & $114.5 \pm 12.7$ & $113.0 \pm 14.7$ & $125.0 \pm 16.6$ \\
\hline & 2010 & $111.5 \pm 11.6$ & $112.0 \pm 12.1$ & $126.0 \pm 15.5$ \\
\hline & 2011 & $112.0 \pm 12.2$ & $114.0 \pm 13.9$ & $125.0 \pm 15.1$ \\
\hline \multirow[t]{5}{*}{ CRP, mg/l } & 2007 & $3.4 \pm 46.6$ & $21.6 \pm 32.9$ & $6.0 \pm 14.0$ \\
\hline & 2008 & $11.1 \pm 22.1$ & $14.0 \pm 19.7$ & $3.7 \pm 4.3$ \\
\hline & 2009 & $11.8 \pm 15.2$ & $15.0 \pm 22.0$ & $5.2 \pm 8.9$ \\
\hline & 2010 & $19.4 \pm 38.4$ & $25.0 \pm 58.8$ & $5.2 \pm 15.3$ \\
\hline & 2011 & $11.9 \pm 20.0$ & $11.3 \pm 25.9$ & $4.1 \pm 6.7$ \\
\hline \multirow[t]{5}{*}{ S-Alb, g/l } & 2007 & $38.4 \pm 5.9$ & $34.2 \pm 5.4$ & $45.0 \pm 4.2$ \\
\hline & 2008 & $38.8 \pm 5.5$ & $36.0 \pm 5.0$ & $45.0 \pm 4.0$ \\
\hline & 2009 & $38.3 \pm 4.5$ & $35.0 \pm 5.0$ & $43.0 \pm 4.0$ \\
\hline & 2010 & $37.1 \pm 6.7$ & $33.0 \pm 7.0$ & $42.0 \pm 4.0$ \\
\hline & 2011 & $38.5 \pm 5.1$ & $35.1 \pm 4.3$ & $42.4 \pm 4.7$ \\
\hline \multirow[t]{5}{*}{ Cholesterol, mmol/l } & 2007 & $4.8 \pm 1.4$ & $5.7 \pm 1.3$ & $5.7 \pm 1.1$ \\
\hline & 2008 & $4.7 \pm 1.3$ & $5.6 \pm 1.3$ & $5.8 \pm 1.2$ \\
\hline & 2009 & $4.8 \pm 1.4$ & $5.7 \pm 1.6$ & $5.6 \pm 1.1$ \\
\hline & 2010 & $4.6 \pm 1.2$ & $5.5 \pm 1.4$ & $5.6 \pm 1.2$ \\
\hline & 2011 & $4.6 \pm 1.1$ & $5.9 \pm 1.6$ & $5.6 \pm 1.3$ \\
\hline \multirow[t]{5}{*}{ PTH, pmol/l } & 2007 & $30.2 \pm 31.1$ & $37.9 \pm 39.0$ & $11.1 \pm 6.6$ \\
\hline & 2008 & $33.3 \pm 34.4$ & $28.8 \pm 32.8$ & $18.6 \pm 25.3$ \\
\hline & 2009 & $34.5 \pm 35.0$ & $26.9 \pm 33.7$ & $17.9 \pm 21.8$ \\
\hline & 2010 & $32.9 \pm 35.8$ & $38.6 \pm 45.3$ & $16.2 \pm 22.0$ \\
\hline & 2011 & $35.4 \pm 39.9$ & $29.5 \pm 29.9$ & $17.2 \pm 15.2$ \\
\hline \multirow[t]{5}{*}{$\mathrm{iCa}, \mathrm{mmol} / \mathrm{l}$} & 2007 & $1.15 \pm 0.16$ & $1.17 \pm 0.15$ & $1.28 \pm 0.09$ \\
\hline & 2008 & $1.16 \pm 0.11$ & $1.14 \pm 0.10$ & $1.31 \pm 0.11$ \\
\hline & 2009 & $1.13 \pm 0.14$ & $1.14 \pm 0.12$ & $1.32 \pm 0.14$ \\
\hline & 2010 & $1.20 \pm 0.15$ & $1.18 \pm 0.12$ & $1.34 \pm 0.14$ \\
\hline & 2011 & $1.17 \pm 0.13$ & $1.14 \pm 0.11$ & $1.29 \pm 0.17$ \\
\hline tCa corrected for Alb, mmol/l & 2011 & $2.59 \pm 0.30$ & $2.48 \pm 0.20$ & $2.39 \pm 0.30$ \\
\hline \multirow[t]{5}{*}{$\mathrm{P}, \mathrm{mmol} / \mathrm{l}$} & 2007 & $1.92 \pm 0.67$ & $1.60 \pm 0.47$ & $1.09 \pm 0.24$ \\
\hline & 2008 & $1.83 \pm 0.55$ & $1.73 \pm 0.49$ & $1.10 \pm 0.30$ \\
\hline & 2009 & $1.93 \pm 0.62$ & $1.73 \pm 0.60$ & $1.10 \pm 0.30$ \\
\hline & 2010 & $1.82 \pm 0.62$ & $1.66 \pm 0.49$ & $1.20 \pm 0.50$ \\
\hline & 2011 & $1.78 \pm 0.59$ & $1.87 \pm 1.52$ & $1.18 \pm 0.35$ \\
\hline
\end{tabular}

Values are represented as mean \pm SD.

\section{Anaemia Management}

Mean $\mathrm{Hb}$ values indicated that $13 \%$ of the $\mathrm{HD}, 13 \%$ of the PD and $4 \%$ of the kidney transplantation patients had severe anaemia $(\mathrm{Hb}<100 \mathrm{~g} / \mathrm{l})$ during the study period (fig. 1a). A high Hb level ( $>125 \mathrm{~g} / \mathrm{l}$ ) was found in $15 \%$ of the HD, 19\% of the PD and $49 \%$ of the kidney transplantation patients (fig. 1b). During the study period, we noticed an improvement in anaemia control (fig. 1a, b). However, Hb in the different centres was separately investigated in 2011, and not all centres achieved the standard of $>80 \%$ of the dialysis patients with an $\mathrm{Hb}$ level 


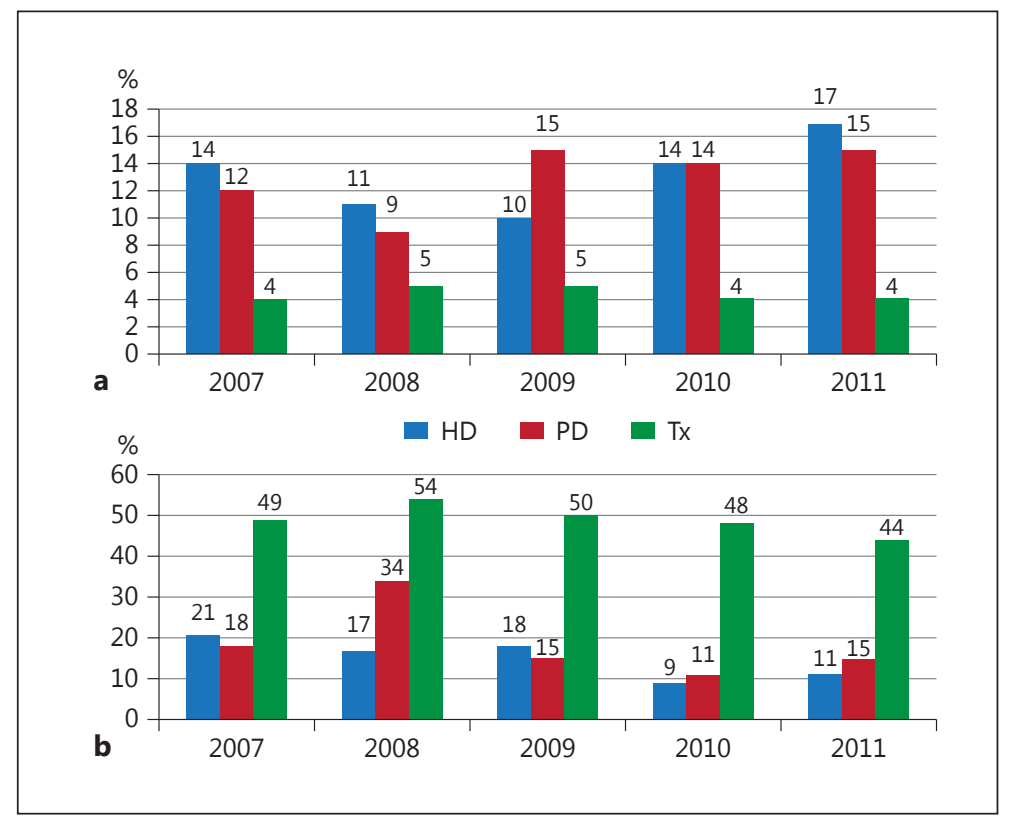

Fig. 1. a Percentages of the HD, PD and transplantation (Tx) patients who had Hb levels $<100 \mathrm{~g} / \mathrm{l}$ during the period of 2007-2011. The 5-year average of the Hb values indicated that $13 \%$ of the HD, $13 \%$ of the PD and $4 \%$ of the Tx patients had severe anaemia. The mean Hb levels of the HD and PD patients were similar and remained at the same level during the 5-year study period. b Percentages of the HD, PD and Tx patients who had $\mathrm{Hb}$ levels $>125 \mathrm{~g} / \mathrm{l}$ during the period of 2007-2011. The 5-year average of the Hb values indicated elevated values ( $>125 \mathrm{~g} / \mathrm{l}$ ) in $15 \%$ of the HD, $10 \%$ of the PD and $49 \%$ of the Tx patients. During the 5 -year study period, a downward trend occurred.

$>100 \mathrm{~g} / \mathrm{l} . \mathrm{Hb}$ levels $<100 \mathrm{~g} / \mathrm{l}$ were found in centre 1 (West Tallinn Central Hospital) in 31\% of the HD patients and in centre 3 (North Estonian Regional Hospital) in 30\% of the PD patients (fig. 2a). High Hb levels (>125 g/l) existed in $17 \%$ of the HD patients and $26 \%$ of the PD patients in centre 1 (fig. 2b). ESA therapy remained almost unchanged in the different RRT treatment cohorts, and the results showed that $93-94 \%$ of the HD, $85-89 \%$ of the PD and $18-21 \%$ of the kidney transplantation patients received erythropoietin (EPO).

\section{Mineral Metabolism}

Mineral metabolism indicator data are summarised in figure 3. The presence of hyperphosphataemia was high in the dialysis patient groups: $73 \%$ of the HD and $63 \%$ of the PD patients had a $\mathrm{p}$ value of $>1.45 \mathrm{mmol} / \mathrm{l}$. Percentages of hyperphosphataemia levels higher than those locally accepted ( $p>1.6 \mathrm{mmol} / \mathrm{l}$ ) were found in $58 \%$ of the HD, $47 \%$ of the PD and in $9 \%$ of the transplantation patients in 2011. During the study period, iCa was almost similar in the different treatment groups. The mean serum iCa remained within the normal range during the investigated years. In addition, iCa values higher than normal were found in $9 \%$ of the HD, $8 \%$ of the PD and $41 \%$ of the kidney transplantation patients.

Similarly, the mean serum tCa was within the normal range in 2011 when tCa values were available in almost all HD (mean $2.27 \pm 0.23 \mathrm{mmol} / \mathrm{l}$ ), PD (mean $2.24 \pm 0.24 \mathrm{mmol} / \mathrm{l}$ ) and kidney transplantation (mean $2.37 \pm 0.20 \mathrm{mmol} / \mathrm{l}$ ) patients. However, assessment revealed that $7 \%$ of the HD, $2 \%$ of the PD and $12 \%$ of the kidney transplantation patients had tCa levels above the normal values. 
Fig. 2. a Percentages of the HD and PD patients in the different nephrology centres who had $\mathrm{Hb}$ levels $<100 \mathrm{~g} / \mathrm{l}$ in 2011. b Percentages of the HD and PD patients in the different nephrology centres who had Hb levels $>125$ $\mathrm{g} / \mathrm{l}$ in 2011.

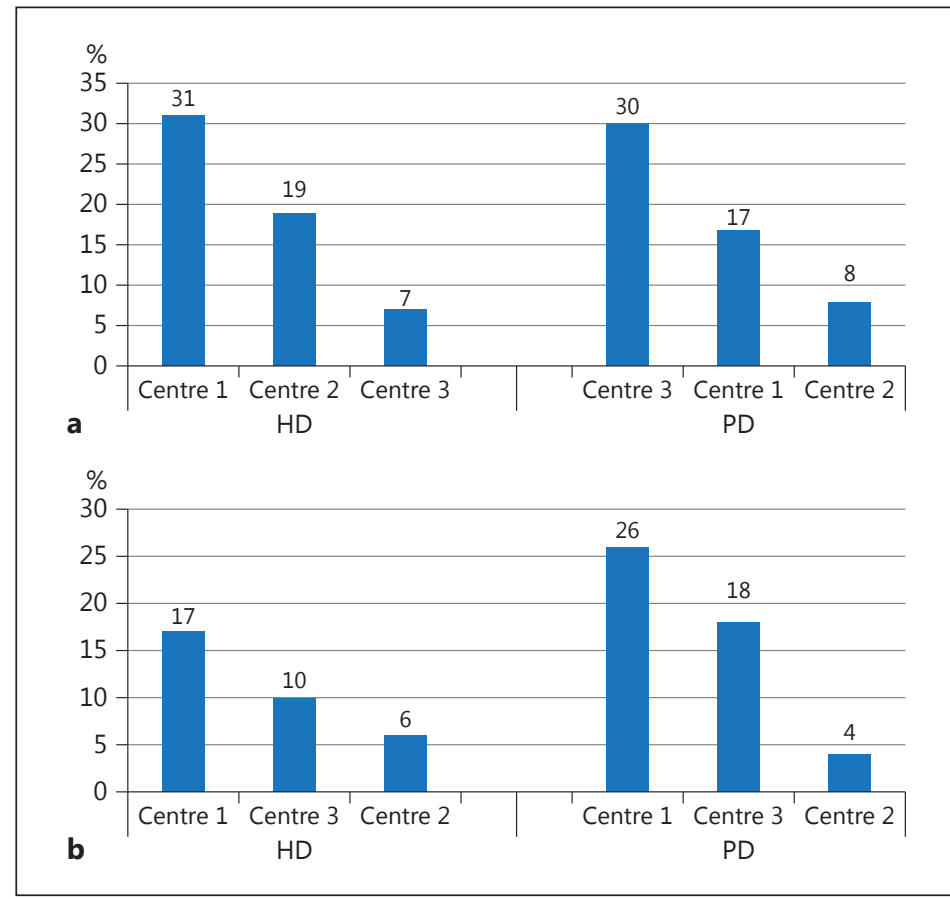

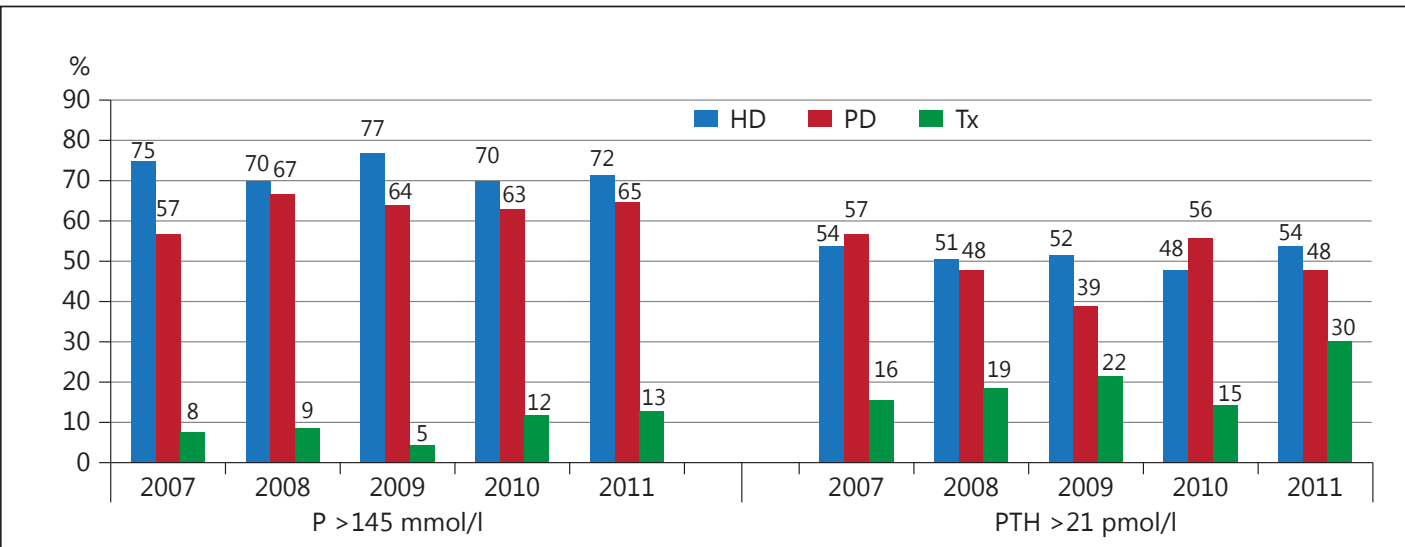

Fig. 3. Percentages of the HD, $P D$ and Tx patients who had $P>1.45 \mathrm{mmol} / \mathrm{l}$ and $\mathrm{PTH}>21 \mathrm{pmol} / \mathrm{l}$ during the period of 2007-2011. Hyperphosphataemia was 73\% in the HD, 63\% in the PD and only $9 \%$ in the Tx patients. Hyperparathyroidism was $52 \%$ in the HD, 50\% in the PD and $20 \%$ in the Tx patients.

In 2007, PTH values were collected in almost all PD (mean $37.91 \pm 4.95 \mathrm{pmol} / \mathrm{l} ; \mathrm{n}=62$ ) and HD (mean $30.24 \pm 2.27 \mathrm{pmol} / \mathrm{l} ; \mathrm{n}=187$ ) patients, but only few doctors measured PTH in their kidney transplantation patients (mean $11.11 \pm 1.56 \mathrm{pmol} / \mathrm{l} ; \mathrm{n}=18$ ). Thus, hyperparathyroidism was present in $52 \%$ of the HD, $50 \%$ of the PD and $20 \%$ of the kidney transplantation patients.

\section{Nutritional Status}

Hypoalbuminaemia was present in $20 \%$ of the HD, $43 \%$ of the PD and only $3 \%$ of the kidney transplantation patients (fig. 4). Five percent of the HD, $2 \%$ of the PD and $3 \%$ of the 
Fig. 4. Percentages of the HD, PD and Tx patients who had albumin levels $<35 \mathrm{~g} / \mathrm{l}$ during the period of 2007-2011. Hypoalbuminaemia was present in $20 \%$ of the HD, $43 \%$ of the PD and only $3 \%$ of the Tx patients.

Fig. 5. Percentages of the different BMI values of the HD, PD and Tx patients in 2010. A BMI $<18.5$ occurred in $5 \%$ of the HD, $2 \%$ of the PD and $3 \%$ of the Tx patients. Most overweight and obese patients (72\%) of the 2010 data were present in the Tx group.
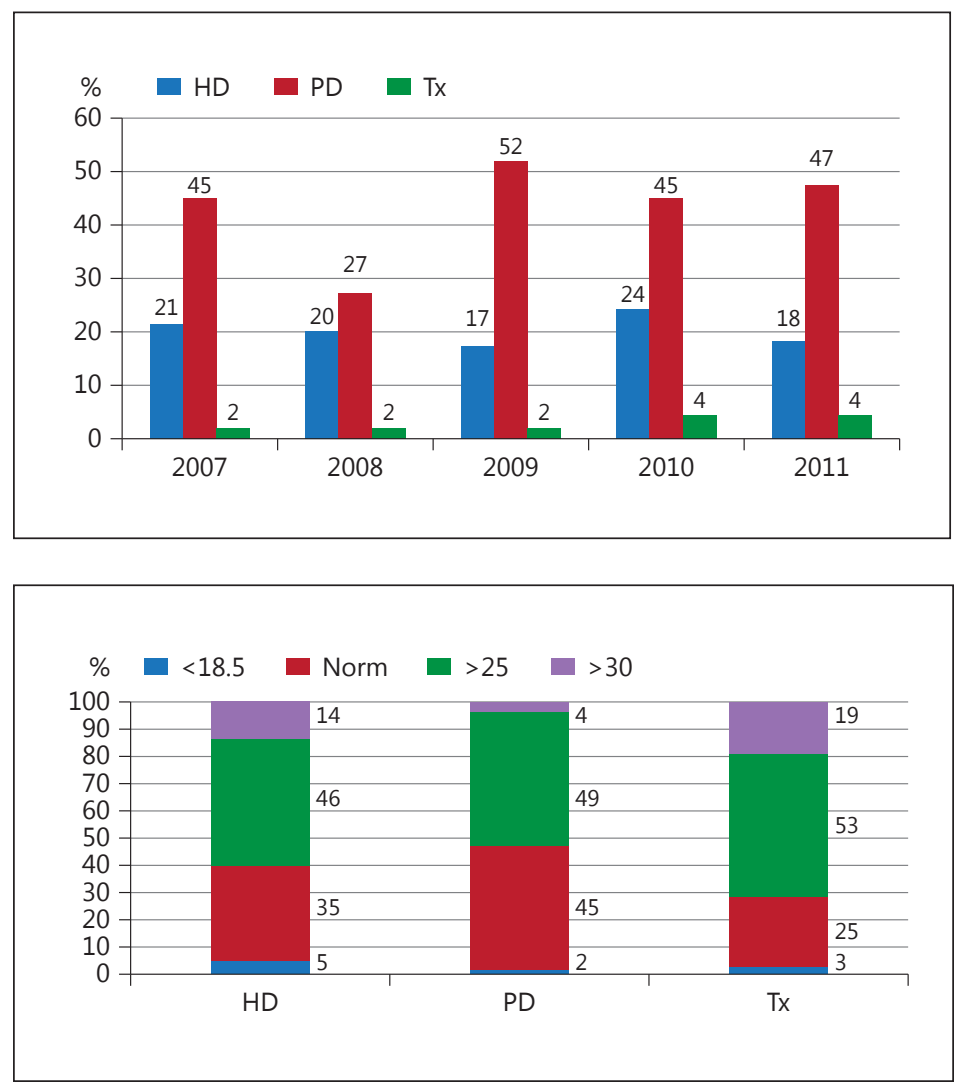

Fig. 6. Percentages of the HD and PD patients who had CRP levels $>5 \mathrm{mg} / \mathrm{l}$ during the period of 2007-2011. The CRP levels were similarly elevated in HD and PD patients (54\%), but only $23 \%$ of the Tx patients had elevated CRP levels during the study period.

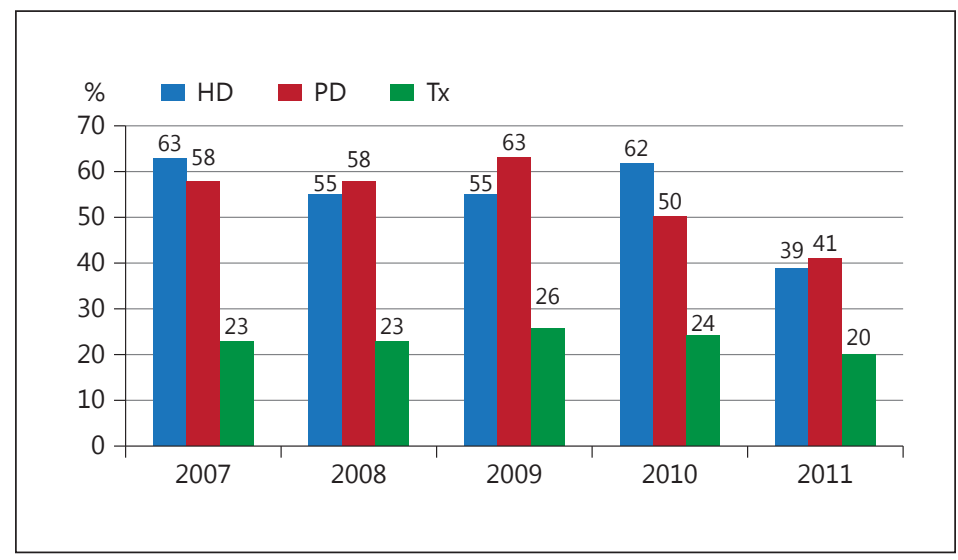

kidney transplantation patients had a BMI $<18.5$. Most obese patients (2010 data) were present among the kidney transplantation patients (fig. 5).

The average levels of cholesterol were within normal limits in all types of RRT patients, and hypercholesterolaemia was seen in $10 \%$ of the HD, 33\% of the PD and $29 \%$ of the kidney transplantation patients. CRP levels ( $>5 \mathrm{mg} / \mathrm{l}$ ) were found to be similarly elevated in both HD and PD patients (average 54\%) (fig. 6).

\section{Kidney Function in Kidney Transplantation Patients}

Serum creatinine (mean \pm SD) in kidney transplantation patients in 2007 was $144 \pm 72$ $\mu \mathrm{mol} / \mathrm{l}$, in $2008146 \pm 79 \mu \mathrm{mol} / \mathrm{l}$, in $2009145 \pm 83 \mu \mathrm{mol} / \mathrm{l}$ and in $2010142 \pm 77 \mu \mathrm{mol} / \mathrm{l}$. The 
Fig. 7. a HD frequency during the period of 2008-2010. Most of the HD patients $(73 \%)$ were dialysed thrice weekly, while only $18 \%$ were dialysed twice weekly during the period of 2008-2010. Only few patients $(9 \%)$ received 4 dialysis sessions/week. b HD access during the period of 2008-2011. More than half (58\%) of the patients had native AVF and only $8 \%$ permanent HD catheters as HD access in 2008. By the end of the study period, a tendency towards less native AVF (52\%) and more permanent catheters $(13 \%)$ and AV grafts (35\%) was noticed.

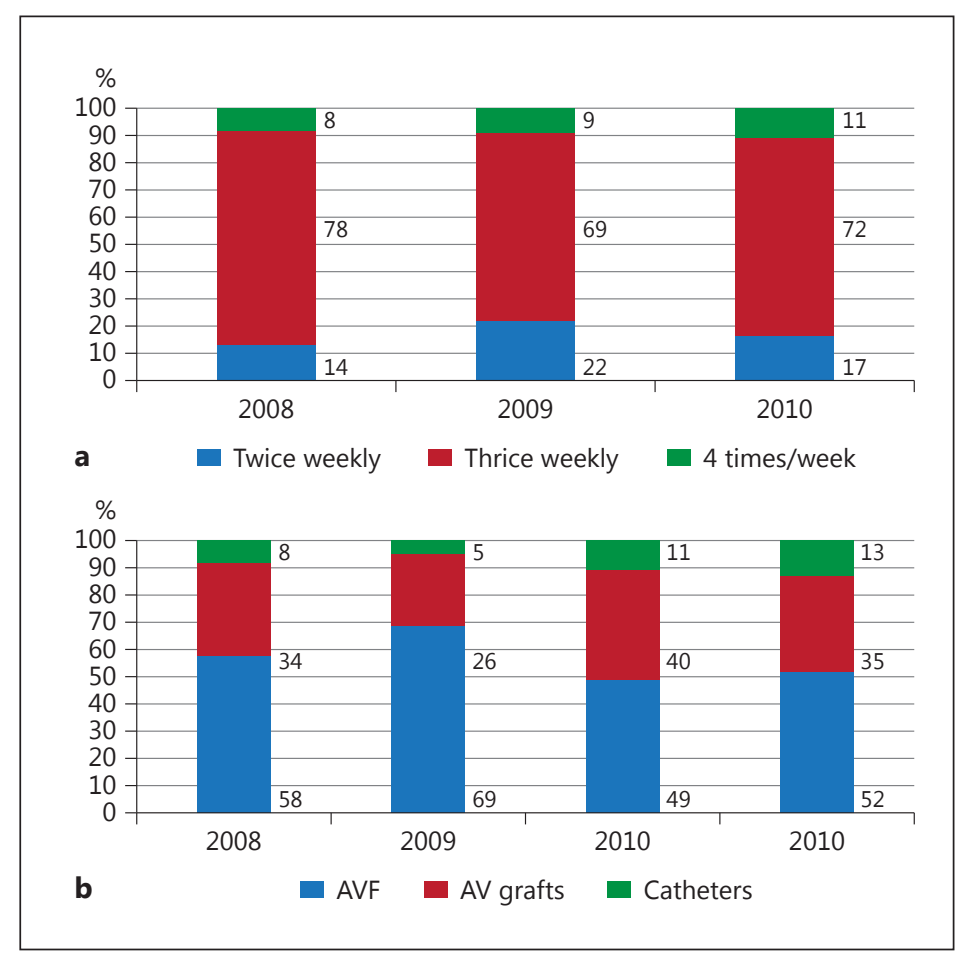

estimated GFR value in 2010 was $56 \pm 23 \mathrm{ml} / \mathrm{min} / 1.73 \mathrm{~m}^{2}$. Most of the kidney transplantation patients (46\%) had a GFR between 30 and $60 \mathrm{ml} / \mathrm{min} / 1.73 \mathrm{~m}^{2}, 40 \%$ had a GFR $>60 \mathrm{ml} /$ $\mathrm{min} / 1.73 \mathrm{~m}^{2}$ and only $14 \%$ had a value $<30 \mathrm{ml} / \mathrm{min} / 1.73 \mathrm{~m}^{2}$.

\section{Delivered Dialysis Dose and Adequacy}

Most of the HD patients (73\%) were dialysed thrice weekly and only 18\% twice weekly during the period of 2008-2010 (fig. 7a). Regular measurements of the delivered HD dose and adequacy were calculated in all dialysis centres and small units, but $65 \%$ had adequate data in 2010 to calculate the URR and equilibrated Kt/V using the single-pool formula with an estimated 30-minute postdialysis urea. Seventy-seven percent of the patients treated for HD in December 2010 achieved a URR of $\geq 65 \%$. The mean Kt/V varied between the centres: $1.72 \pm 0.4 / \mathrm{h}$ in centre 2 (Tartu University Hospital), $1.74 \pm 0.25 / \mathrm{h}$ in one small HD unit, $1.36 \pm$ $0.23 / \mathrm{h}$ in another small unit and $1.1 \pm 0.4 / \mathrm{h}$ in centre 3 .

\section{Vascular Access}

Details of vascular access used for HD patients were collected in the years 2008-2011. More than half (58\%) of the patients had native arteriovenous fistulae (AVF) and only $8 \%$ had a permanent HD catheter as HD access in Estonia in 2008 (fig. 7b).

\section{Discussion}

In the current study, we assessed CPI in RRT patients and reported longitudinal practice patterns and guideline adherence on the country and local-centre level in Estonia. Our study showed a significant improvement in the mean values of the various CPI during the investigation period. First, the mean $\mathrm{Hb}$ outcomes for patients on RRT in Estonia were largely 
compliant with the guidelines' minimum standard of $\mathrm{Hb} 100 \mathrm{~g} / \mathrm{l}$. Only $13 \%$ of the dialysis and $4 \%$ of the kidney transplantation patients had severe anaemia if taken as the mean of the studied years. However, if $\mathrm{Hb}$ in the different centres was separately investigated, not all centres achieved the standard of $>80 \%$ of the dialysis patients with $\mathrm{Hb}$ levels $>100 \mathrm{~g} / \mathrm{l}$. The median $\mathrm{Hb}$ level of the patients receiving HD was $112.0 \mathrm{~g} / \mathrm{l}$ and that of those receiving PD was $114.0 \mathrm{~g} / \mathrm{l}$. These results are comparable with data from the UK, in which the mean Hb level was found to be $11.2 \mathrm{~g} / \mathrm{dl}$ in HD and $11.4 \mathrm{~g} / \mathrm{dl}$ PD patients in 2011 [11]. The Hb level targeted by Estonian nephrologists during the current study ranged from 110 to $120 \mathrm{~g} / \mathrm{l}$. A metaanalysis by Phrommintikul et al. [12] led to the conclusion that the patients in the higher $\mathrm{Hb}$ target group were at a significantly greater risk of all-cause mortality, arteriovenous access thrombosis and poorly controlled blood pressure, which could contribute to the increased risk of mortality. The ERBP anaemia group recommendation is an $\mathrm{Hb}$ value of $11-12 \mathrm{~g} / \mathrm{dl}$ and it should not be $>13 \mathrm{~g} / \mathrm{dl}$ [13]. Second, fortunately the percentage of patients who had $\mathrm{Hb}$ levels $>125 \mathrm{~g} / \mathrm{l}$ showed a downward trend during the investigated years. The proportion of patients receiving ESA therapy in Estonia (93-94\% of the HD and 85-89\% of the PD patients) is somewhat higher than in the UK ( $90 \%$ of the HD and $73 \%$ of the PD patients) [4]. Some studies showed that despite the supposition that renal transplant recipients receive more care from nephrologists, an appropriate EPO therapy is provided only in $25 \%$ of these patients [14]. In our study, 18 and $21 \%$ of the kidney transplantation patients received EPO, which was less than among the dialysis patients.

The percentage of hyperphosphataemia was 58\% in the HD and $47 \%$ in the PD patients, which is similar to the captivating European study COSMOS [15] in which approximately 50\% of the patients had baseline P levels above the target range. However, hypercalcaemia was a problem only for a small proportion of the dialysis patients; $12 \%$ of the kidney transplantation patients had iCa levels above the normal values, and hyperphosphataemia was present in 9\%. In addition, Sprague et al. [16] demonstrated that abnormal bone and mineral metabolism exists in patients after kidney transplantation and suggests the need for treatment of this condition. We conclude that the degree of control of mineral metabolism in our patients is still insufficient, and a large percentage of the RRT patients did not achieve the recommended targets. Despite the fact that during the first 4 years of the investigation period only calcium-containing phosphate binders were available in Estonia because non-calciumbinding agents as well as cinacalcet have become available only since January 2011, we did not see a significant improvement in the laboratory values within 1 year.

A low S-Alb concentration is by far the strongest predictor of mortality and poor outcomes in adult ESRD patients on maintenance dialysis when compared to any other risk factors [17, 18]. In our dialysis patients, hypoalbuminaemia occurred frequently ( $20 \%$ of the HD and $43 \%$ of the PD patients). Higher CRP values were found in dialysis patients (in 54\%). Panichi et al. [19] found similar results in their study: the analysis of the CRP values in the clinically stable patients showed that an unexpectedly high proportion (47\%) had CRP values of $>5 \mathrm{mg} / \mathrm{l}$ (taken as the upper limit in normal human subjects).

Wasting is prevalent among patients with CKD. In a report by Kalantar-Zadeh et al. [20], $18-75 \%$ of the adults with end-stage renal disease undergoing maintenance dialysis showed some evidence of wasting. Based on the collected CPI data, we cannot describe protein energy wasting occurrence correctly in our RRT population. A low BMI was only found in $5 \%$ of the HD and $2 \%$ of the PD patients. On the other hand, most of the obese patients, namely $72 \%$, were among the kidney transplantation patients. Low serum cholesterol, which has also been proposed as a biochemical indicator of protein energy wasting, was found in a very small proportion of patients, but elevated CRP levels were found roughly in half of the dialysis patients and in one quarter of the kidney transplantation patients. A significant number of studies on CKD report low serum total cholesterol values to be associated with malnutrition, 
chronic inflammation and increased mortality $[21,22]$. Difficulties in controlling the cholesterol level are usually detected in kidney transplantation patients in whom such difficulties might be caused by the adverse effects of immunosuppressive treatments with corticosteroids, calcineurin inhibitors and mammalian target of rapamycin antagonists. Hypercholesterolaemia was found in $29 \%$ of our kidney transplantation patients, which is comparable to another report [23].

Most of the patients (73\%) were dialysed thrice weekly, and Kt/V was excellent in centre 2 and some small units. However, a surprising finding was the rather limited use of equilibrated Kt/V as recommended by the EBPG in daily practice. Despite the fact that the use of the URR is not recommended by the EBPG, it was used by local guidelines to measure urea removal, and the results showed good adherence with these guidelines. Recent studies have demonstrated a great international variability in weekly HD duration and some discrepancies between current practices and recommendations of international guidelines [24,25]. By the end of the study, a tendency towards less native AVF and more permanent catheters and AV grafts was noticed. These are areas that might be improved in the future.

\section{Conclusion}

The study gives a general overview about the RRT practice patterns in Estonia. Several improvements occurred during the study period, although significant inter-centre variation in the achievement of anaemia and mineral metabolism as well as HD adequacy variables was found. Collection and evaluation of the CPI of RRT patients is an important improvement in the epidemiological research as it enlarges the knowledge and significantly raises the awareness of nephrologists.

\section{Acknowledgement}

We thank all nephrologists who participated in the creation of the RRT database.

\section{Disclosure Statement}

The authors have no conflicts of interest to declare.

\section{References}

1 ERA-EDTA registry annual report 2011. 2013.

-2 Locatelli F, Aljama P, Barany P, Canaud B, Carrera F, Eckardt KU, Horl WH, Macdougal IC, Macleod A, Wiecek A, Cameron S: Revised European Best Practice Guidelines for the management of anaemia in patients with chronic renal failure. Nephrol Dial Transplant 2004;19(Suppl 2):ii1-ii47.

-3 Kidney Disease: Improving Global Outcomes (KDIGO) CKD-MBD Work Group: KDIGO clinical practice guideline for the diagnosis, evaluation, prevention, and treatment of hronic kidney disease-mineral and bone disorder (CKD-MBD). Kidney Int Suppl 2009;113:S1-S130.

4 Port FK, Pisoni RL, Bommer J, Locatelli F, Jadoul M, Eknoyan G, Kurokawa K, Canaud BJ, Finley MP, Young EW: Improving outcomes for dialysis patients in the international dialysis outcomes and practice patterns study. Clin J Am Soc Nephrol 2006;1:246-255.

-5 Jurkovitz CT, Abramson JL, Vaccarino LV, Weintraub WS, McClellan WM: Association of high serum creatinine and anemia increases the risk of coronary events: results from the prospective community-based atherosclerosis risk in communities (ARIC) study. J Am Soc Nephrol 2003;14:2919-2925. 
6 Phelan PJ, O’Kelly P, Walshe JJ, Conlon PJ: The importance of serum albumin and phosphorous as predictors of mortality in ESRD patients. Ren Fail 2008;30:423-429.

7 WHO: Obesity. 2013. http://www.who.int/topics/obesity/en/.

-8 Levey AS, Stevens LA, Schmid CH, Zhang YL, Castro AF, 3rd, Feldman HI, Kusek JW, Eggers P, Van Lente F, Greene T, Coresh J: A new equation to estimate glomerular filtration rate. Ann Intern Med 2009;150:604-612.

9 Eesti Nefroloogide Selts 2001 Diagnostika - ja ravijuhised nefroloogias. Tallinn, 2001, Estonia.

10 Rosenberg M: Epidemiological data chronic kidney diseases in Estonia annual report 2012. www.nefro.ee.

11 Rao A, Gilg J, Williams A: UK Renal Registry 15th annual report: chapter 6 haemoglobin, ferritin and erythropoietin amongst uk adult dialysis patients in 2011: national and centre-specific analyses. Nephron Clin Pract 2013;123(Suppl 1):125-150.

-12 Phrommintikul A, Haas SJ, Elsik M, Krum H: Mortality and target haemoglobin concentrations in anaemic patients with chronic kidney disease treated with erythropoietin: a meta-analysis. Lancet 2007;369:381-388.

13 Locatelli F, Covic A, Eckardt KU, Wiecek A, Vanholder R: Anaemia management in patients with chronic kidney disease: a position statement by the Anaemia Working Group of European Renal Best Practice (ERBP). Nephrol Dial Transplant 2009;24:348-354.

$\checkmark 14$ Yorgin PD, Scandling JD, Belson A, Sanchez J, Alexander SR, Andreoni KA: Late post-transplant anemia in adult renal transplant recipients. An under-recognized problem? Am J Transplant 2002;2:429-435.

15 Fernandez-Martin JL, Carrero JJ, Benedik M, Bos WJ, Covic A, Ferreira A, Floege J, et al: The dialysis scenario of CKD-MBD in Europe. Nephrol Dial Transplant 2013;28:1922-1935.

16 Sprague SM, Belozeroff V, Danese MD, Martin LP, Olgaard K: Abnormal bone and mineral metabolism in kidney transplant patients - a review. Am J Nephrol 2008;28:246-253.

17 Owen WF, Jr, Lew NL, Liu Y, Lowrie EG, Lazarus JM: The urea reduction ratio and serum albumin concentration as predictors of mortality in patients undergoing hemodialysis. N Engl J Med 1993;329:1001-1006.

18 Beddhu S, Kaysen GA, Yan G, Sarnak M, Agodoa L, Ornt D, Cheung AK: Association of serum albumin and atherosclerosis in chronic hemodialysis patients. Am J Kidney Dis 2002;40:721-727.

19 Panichi V, Migliori M, De Pietro S, Metelli MR, Taccola D, Perez R, Palla R, Rindi P, Cristofani R, Tetta C: Plasma C-reactive protein in hemodialysis patients: a cross-sectional, longitudinal clinical survey. Blood Purif 2000; 18:30-36.

-20 Kalantar-Zadeh K, Ikizler TA, Block G, Avram MM, Kopple JD: Malnutrition-inflammation complex syndrome in dialysis patients: causes and consequences. Am J Kidney Dis 2003;42:864-881.

-21 Afzali B, Haydar AA, Vinen K, Goldsmith DJ: From Finland to fatland: beneficial effects of statins for patients with chronic kidney disease. J Am Soc Nephrol 2004;15:2161-2168.

22 Lowrie EG, Lew NL: Death risk in hemodialysis patients: the predictive value of commonly measured variables and an evaluation of death rate differences between facilities. Am J Kidney Dis 1990;15:458-482.

-23 Tse KC, Lam MF, Yip PS, Li FK, Lai KN, Chan TM: A long-term study on hyperlipidemia in stable renal transplant recipients. Clin Transplant 2004;18:274-280.

24 Port FK, Wolfe RA, Hulbert-Shearon TE, McCullough KP, Ashby VB, Held PJ: High dialysis dose is associated with lower mortality among women but not among men. Am J Kidney Dis 2004;43:1014-1023.

25 Couchoud C, Kooman J, Finne P, Leivestad T, Stojceva-Taneva O, Ponikvar JB, Collart F, Kramar R, de Francisco A, Jager KJ: From registry data collection to international comparisons: examples of haemodialysis duration and frequency. Nephrol Dial Transplant 2009;24:217-224. 